\title{
ANALISIS SISA PEMBAGIAN DARI SIGMA 13i PANGKAT $m$ DENGAN $i$ DARI 1 SAMPAI $n$ OLEH PEMBAGI 2
}

\author{
Satria Riki Mustafa ${ }^{1)}$ \\ ${ }^{1}$ Dosen Program Studi Teknik Informatika, Fakultas Ilmu Komputer Universitas Pasir Pengaraian \\ e-mail: satriarikimustafa@gmail.com
}

\begin{abstract}
Divisibility of finite sums of power of integers such as $\sum_{i=1}^{n}(2 i)^{m}, \sum_{i=1}^{n}(2 i-1)^{m}, \sum_{i=1}^{n}(3 i)^{m}$, $\sum_{k=1}^{n}(4 k)^{m}$, and $\sum_{k=1}^{n}(5 k)^{m}$ has been developed by authors in some books and articles. In this article will be discussion residual of result division $\sum_{i=1}^{n}(13 i)^{m}$ divisible by two by using divisibility concept and formulate it based on residual of result division that is listed into tables.
\end{abstract}

Keywords: sums of power of integers, divisibility of numbers, Integer squences

\section{PENDAHULUAN}

Konsep pembagian atau keterbagian tak jarang kita temui pada kehidupan seharihari. Keterbagian atau divisibility merupakan sudut pandang matematika yang mempelajari suatu bilangan yang habis dibagi oleh bilangan lain. Beberapa peneliti sudah ada meneliti mengenai jumlah bilangan bulat berpangkat dibagi oleh suatu bilangan bulat tertentu. Pada paragaf selanjutnya akan dijelaskan bebeapa hasil penelitian yang menjadi rujukan. $\begin{array}{rrr}\text { Pada } & \text { penelitian } & \text { Gulliver (2010) } \\ \text { dijelaskan } & \text { tentang } & \text { keterbagian }\end{array}$ $\sum_{i=1}^{n}(2 i)^{m}$ oleh pembagi 3 dan 5. Penelitian ini dilakukan dengan cara mendaftarkan sisa pembagian ke dalam bentuk tabel dengan $m$ $=1,2,3, \ldots, 12$ dan $n=1,2,3, \ldots, 10$. Setelah didaftarkan kemudian Guliver memperhatikan pola sisa pembagian untuk $m$ dan $n$ berikutnya sehingga bisa diperoleh keterbagian $\sum_{i=1}^{n}(2 i)^{m}$ oleh pembagi 3 dan 5 .

Pada penelitian Gulliver (2010) mengenai keterbagian $\sum_{i=1}^{n}(2 i-1)^{m}$ oleh pembagi 10, 3, dan 5. Peneltian ini dilakukan dengan cara yang sama seperti cara Gulliver meneliti mengenai keterbagian $\sum_{i=1}^{n}(2 i)^{m}$ oleh pembagi 3 dan 5 yaitu, dengan cara mendaftarkan sisa pembagian kedalam bentuk tabel dengan $m=1,2,3, \ldots, 12$ dan $n=1,2,3, \ldots, 12$. Setelah didaftarkan
Guliver memperhatikan pola sisa pembagian untuk $m$ dan $n$ selanjutnya sehingga dapat ditentukan keterbagian $\sum_{i=1}^{n}(2 i-1)^{m}$ oleh pembagi 10, 3, dan 5 .

Selanjutnya penelitian Gulliver (2012) mengenai keterbagian $\sum_{i=1}^{n}(3 i)^{m}$ oleh pembagi 4 dan 5. Peneltian ini dilakukan dengan cara yang sama seperti cara yang sebelumnya yaitu dengan mendaftarkan sisa pembagian ke dalam bentuk tabel dengan $m=1,2,3, \ldots, 12$ dan $n=$ $1,2,3, \ldots, 15$. Setelah didaftarkan Guliver memperhatikan pola sisa pembagian untuk $m$ dan $n$ selanjutnya sehingga dapat ditentukan keterbagian $\sum_{i=1}^{n}(3 i)^{m}$ oleh pembagi 4 dan 5.

Penelitian Suprijanto dan Rusliansyah (2014) mengenai keterbagian $\sum_{k=1}^{n}(4 k)^{m}$ oleh pembagi 10, 5, dan 3. Mereka menyatakan keterbagian tersebut pada dua kasus, yaitu kasus $m$ tetap dan $n$ tetap. Untuk kasus $n$ tetap, sisa pembagian didaftarkan ke dalam bentuk tabel dengan $m=1,2,3, \ldots, 12$ dan $n=1,2,3, \ldots, 10$. Berdasarkan tabel tersebut dapat ditentukan pola sisa pembagian untuk $m$ dan $n$ berikutnya sehingga dapat ditentukan keterbagian tersebut. Untuk kasus $n$ tetap, ditentukan beberapa keterbagian untuk nilai $m$ tertentu.

Selanjutnya penelitian Suprijanto (2015) mengenai keterbagian $\sum_{k=1}^{n}(5 k)^{m}$ oleh pembagi 10 dan 3. Penelitian 
keterbagian tersebut dilakukan dengan cara yang sama seperti sebelumnya dengan membaginya pada dua kasus, yaitu kasus $m$ tetap dan $n$ tetap. Untuk kasus $n$ tetap, sisa pembagian didaftarkan ke dalam bentuk tabel dengan $m=1,2,3, \ldots, 10$ dan $n=1,2,3, \ldots, 10$. Berdasarkan tabel tersebut dapat diperoleh pola sisa pembagian untuk $m$ dan $n$ berikutnya sehingga dapat ditentukan keterbagian tersebut. Untuk kasus $n$ tetap, ditentukan beberapa keterbagian untuk nilai $m$ tertentu.

Masih ada beberapa bentuk keterbagian lainnya yang bisa ditentukan untuk nilai $n$ atau $m$ tetap dengan memperhatikan jumlah modulo setiap bilangan atau dengan menentukan bentuk rumus paling mendekati untuk nilai $m$ tetap. Selain itu, bisa menghitung $\sum_{i=1}^{n}(p i)^{m}$ dengan $p$ lebih besar dari 3. Untuk $p=4$ $p=5$ dan $p=7$ telah diselidiki oleh peneliti sebelumnya.

Dari pembahasan diatas maka penulis akan membahas sisa pembagian dari $\sum_{i=1}^{n}(13 i)^{m}$ oleh pembagi 2 dengan menggunakan konsep keterbagian serta memformulasikannya berdasarkan tabel sisa pembagian.

Aksoy dan Khamsi (2010) serta Potter (1998) mengatakan barisan merupakan suatu fungsi dengan domainnya adalah himpunan $N$ bilangan asli, kemudian Irawati dkk (2008) mengatakan bahwa barisan bilangan adalah suatu susunan bilangan yang dibentuk menurut suatu urutan tertentu. Sedangkan Mashadi dan Hadi (2017) mendefenisikan barisan bilangan real sebagai fungsi pada himpunan bilangan asli $N$ dengan daerah jelajah termuat di dalam himpunan bilangan real $R$. Berdasarkan polanya, barisan bilangan dibagi menjadi 2 bagian, yaitu barisan aritmatika dan barisan geometri.

Membahas tentang pembagian maka teorema yang menjadi dasar kita adalah algoritma pembagian. Secara umum dikemukakan bahwa sebuah bilangan bulat dapat dibagi oleh bilangan bulat positif $b$ yang sisanya lebih kecil daripada b. Untuk lebih jelasnya sebagai berikut:

Algoritma pembagian telah dibahas dalam beberapa buku teks antara lain Baker (1984), Burton (2010) dan Koshy (2007) menyatakan bahwa Algoritma Pembagian dijelaskan pada teorema 1 dan sifatnya dijelaskan pada teorema 2.

Teorema 1 (Algoritma Pembagian). Diberikan dua bilangan bulat $a$ dan $b$, dengan $b>0$, terdapat bilangan bulat unik $q$ dan $r$ sedemikian hingga,

$$
a=q b+r \text { dengan } 0 \leq r<n
$$

Bilangan bulat $q$ disebut pembagi dan $r$ disebut sisa dalam pembagian $a$ oleh b. Jika $r=0$ maka dikatakan $a$ habis dibagi oleh $b$ dan ditulis $b \mid a$. Jika $r \neq 0$ maka ditulis $b \nmid a$.

Teorema 2 (Sifat-sifat keterbagian).Untuk $a, b$ dan $c$ bilangan bulat, berlaku :

(a) $a|0,1| a, a \mid a$.

(b) $a \mid 1$ jika dan hanya jika $a= \pm 1$.

(c) jika $a \mid b$ dan $c \mid d$, maka $a c \mid b d$.

(d) Jika $a \mid b$ dan $b \mid c$, maka $a \mid c$.

(e) $a \mid b$ dan $b \mid a$ jika dan hanya jika $a= \pm b$.

(f) Jika $a \mid b$ dan $b \neq 0$, maka $|a|=|b|$.

(g) Jika $a \mid b$ dan $b \mid c$, maka $a \mid(b x+c y)$ untuk semua bilangan bulat $x$ dan $y$

Kongruen secara umum dapat diartikan adanya kesamaan sifat dari dua benda Dua buah bilangan dikatakan kongruen jika dan hanya jika memiliki sisa yang sama apabila dibagi oleh suatu bilangan bulat. Kekongruenan telah dibahas dalam beberapa buku teks antara lain Burton (2010), Clark (2003) dan Stark (1998).

Definisi 1 (Kekongruenan). Misalkan n bilangan bulat positif, dua bilangan bulat a dan $b$ dikatakan kongruen modulo $n$, dinotasikan dengan,

$$
a \equiv b(\bmod n)
$$

jika n membagi $a-b$; yaitu terdapat bilangan bulat $k$ sedemikian hingga $a-b=k n$. 


\section{METODE PENELITIAN}

Penelitian ini berbentuk studi literatur dengan mempelajari buku teks dan artikel yang berkaitan dengan masalah ini. Adapun langkah-langkah yang dilakukan dalam penelitian ini adalah sebagai berikut:

1. Menentukan sisa pembagian $\sum_{i=1}^{n}(13 i)^{m}$ oleh 2 kemudian mendaftarkan sisa pembagian tersebut ke dalam bentuk tabel.

2. Menentukan kelas modulo untuk setiap pembagi 2 berdasarkan tabel tersebut.

3. Menganalisis sisa pembagian $\sum_{i=1}^{n}(13 i)^{m}$ oleh pembagi 2 dengan menggunakan Teorema Algoritma Pembagian.

4. Mendaftarkan sisa pembagian dari masing-masing pembagi ke dalam bentuk tabel.

5. Menentukan karakteristik keterbagian $\sum_{i=1}^{n}(13 i)^{m}$ oleh pembagi 2 untuk setiap $n$.

\section{HASIL DAN PEMBAHASAN}

Untuk menentukan sisa pembagian dari $\sum_{i=1}^{n}(13 i)^{m}$ oleh pembagi 2 untuk $m=1$ dilakukan dengan cara sebagai berikut:

Pada tahap awal akan dicari sisa pembagian $\sum_{i=1}^{n} 13 i=\frac{13 n(n+1)}{2}$ oleh pembagi 2 . Dikarenakan $\sum_{i=1}^{n} 13 i=\frac{13 n(n+1)}{2}$ memiliki penyebut 2 dan akan dibagi oleh pembagi 2 , hasil perkalian dari penyebut dan pembagi tersebut adalah 4, maka $n$ yang memungkinkan untuk membagi berada pada kelas modulo $4, n=4 k 4 k+1,4 k+2,4 k+3$ dengan $k \geq 0, n \in Z^{+}$.

Selanjutnya untuk $n=4 k$ diperoleh,

$$
\begin{aligned}
\sum_{i=1}^{n} 13 i & =13 \frac{n(n+1)}{2} \\
& =\frac{13.4 k(4 k+1)}{2} \\
& =13.2 k(4 k+1) \\
& =2.13 k(4 k+1) \\
& =2 K
\end{aligned}
$$

Jadi $\sum_{i=1}^{n} 13 i$ habis dibagi 2 untuk $n=4 k$
Selanjutnya untuk $n=4 k+1$ diperoleh,

$$
\begin{aligned}
\sum_{i=1}^{n} 13 i & =13 \frac{n(n+1)}{2} \\
& =\frac{13 \cdot(4 k+1)(4 k+2)}{2} \\
& =13\left(4 k^{2}+1\right)(2 k+1) \\
& =13\left(8 k^{2}+6 k+1\right) \\
& =13\left(8 k^{2}+6 k\right)+13 \\
& =2\left(13\left(4 k^{2}+3 k\right)+6\right)+1 \\
& =2 K+1
\end{aligned}
$$

Jadi $\sum_{i=1}^{n} 13 i$ tidak habis dibagi 2 untuk $n=$ $4 k+1$

Selanjutnya untuk $n=4 k+2$ diperoleh,

$$
\begin{aligned}
\sum_{i=1}^{n} 13 i & =13 \frac{n(n+1)}{2} \\
& =\frac{13 \cdot(4 k+2)(4 k+3)}{2} \\
& =13(2 k+1)(4 k+3) \\
& =13\left(8 k^{2}+10 k+3\right) \\
& =13\left(8 k^{2}+10 k\right)+39 \\
& =2\left(13\left(4 k^{2}+5 k\right)+19\right)+1 \\
& =2 K+1
\end{aligned}
$$

Jadi $\sum_{i=1}^{n} 13 i$ tidak habis dibagi 2 untuk $n$ $=4 k+2$

Sisa pembagian $\sum_{i=1}^{n}(13 i)$ untuk $n=4 k+3$ dapat dibuktikan dengan cara yang sama, sehingga dapat disimpulkan $2 \mid \sum_{i=1}^{n}(13 i)$ untuk $n=4 k, 4 k+3$ dengan $k \geq 0$.

Begitu pula untuk hasil pembagian $\sum_{i=1}^{n}(13 i)^{2}, \sum_{i=1}^{n}(13 i)^{3}, \ldots, \sum_{i=1}^{n}(13 i)^{m}$ oleh pembagi 2 dapat diperoleh dengan cara yang sama seperti mencari hasil pembagian $\sum_{i=1}^{n}(13 i)$ oleh pembagi 2 . Kemudian hasil pembagian didaftarkan kedalam bentuk tabe seperti tabel 1. Hal ini dilakukan untuk mempermudah menganalisi sisa pembagiannya. Berkut ini adalah sisa pembagian $\quad \sum_{i=1}^{n}(13 i)^{m}$ dibagi oleh $n=1,2,3, \ldots, 10$ dan $m=1,2,3, \ldots, 10$ terlihat pada tabel 1 . 
Tabel 1. Sisa Pembagian Dua

\begin{tabular}{|c|c|c|c|c|c|c|c|c|c|c|}
\hline \multirow{2}{*}{$\boldsymbol{M}$} & \multicolumn{10}{|c|}{ Tabel 1. Sisa Pembagian Dua } \\
\cline { 2 - 11 } & $\mathbf{1}$ & $\mathbf{2}$ & $\mathbf{3}$ & $\mathbf{4}$ & $\mathbf{5}$ & $\mathbf{6}$ & $\mathbf{7}$ & $\mathbf{8}$ & $\mathbf{9}$ & $\mathbf{1 0}$ \\
\hline $\mathbf{1}$ & 1 & 1 & 0 & 0 & 1 & 1 & 0 & 0 & 1 & 1 \\
\hline $\mathbf{2}$ & 1 & 1 & 0 & 0 & 1 & 1 & 0 & 0 & 1 & 1 \\
\hline $\mathbf{3}$ & 1 & 1 & 0 & 0 & 1 & 1 & 0 & 0 & 1 & 1 \\
\hline $\mathbf{4}$ & 1 & 1 & 0 & 0 & 1 & 1 & 0 & 0 & 1 & 1 \\
\hline $\mathbf{5}$ & 1 & 1 & 0 & 0 & 1 & 1 & 0 & 0 & 1 & 1 \\
\hline $\mathbf{6}$ & 1 & 1 & 0 & 0 & 1 & 1 & 0 & 0 & 1 & 1 \\
\hline $\mathbf{7}$ & 1 & 1 & 0 & 0 & 1 & 1 & 0 & 0 & 1 & 1 \\
\hline $\mathbf{8}$ & 1 & 1 & 0 & 0 & 1 & 1 & 0 & 0 & 1 & 1 \\
\hline $\mathbf{9}$ & 1 & 1 & 0 & 0 & 1 & 1 & 0 & 0 & 1 & 1 \\
\hline $\mathbf{1 0}$ & 1 & 1 & 0 & 0 & 1 & 1 & 0 & 0 & 1 & 1 \\
\hline
\end{tabular}

Dapat dilihat pada tabel 1 bahwa kolom 3, 4, 7, 8 mempunyai angka terakhir 0 . Jadi , untuk , untuk $n=4 r$ atau $n=4 r-1$ dimana $r \geq 1$ maka 2 dapat membagi barisan bilangan tersebut seperti Teorema 3 berikut:

Teorema 3. Untuk $n$ dan $r$ bilangan bulat positif, $r \geq 1$ dan $m=1,2,3, \ldots, 10$ berlaku

2| $\sum_{i=1}^{n}(13 i)^{m}$ untuk $n=4 r$ atau $n=4 r-1$

Bukti. Pembuktian Teorema 3 untuk $m=1$ diperoleh dengan mensubstitusikan $n=4 r$ ke dalam persamaan $\quad \sum_{i=1}^{n} 13 i=13 \frac{n(n+1)}{2}$ sebagai berikut:

$$
\begin{aligned}
\sum_{i=1}^{n} 13 i & =13 \frac{n(n+1)}{2} \\
& =\frac{13 \cdot 4 r(4 r+1)}{2} \\
& =2.13 r(13 r+1) \\
& =2 R
\end{aligned}
$$

Jadi untuk $R$ suatu bilangan bulat diperoleh bahwa $\sum_{i=1}^{n} 13 i$ habis dibagi 2 untuk $n=4 r$.

Kemudian dengan mensubstitusikan $n=4 r-1 \quad$ ke dalam persamaan $\sum_{i=1}^{n} 13 i=13 \frac{n(n+1)}{2}$ diperoleh:

$$
\begin{aligned}
\sum_{i=1}^{n} 13 i & =13 \frac{n(n+1)}{2} \\
& =\frac{13 \cdot(4 r-1)(4 r)}{2} \\
& =2.13(2 r)(4 r-1) \\
& =2 R
\end{aligned}
$$

Jadi untuk $R$ suatu bilangan bulat diperoleh bahwa $\sum_{i=1}^{n} 13 i$ habis dibagi 2 untuk $n=4 r-1$, sehingga terbukti Teorema 3 untuk $\sum_{i=1}^{n}(13 i)^{m}$ dengan $m=1$.

Pembuktian Teorema 3 untuk $m=2$ diperoleh dengan mensubstitusikan $n=4 r$ ke dalam persamaan $\sum_{i=1}^{n}(13 i)^{2}=\frac{169 n(n+1)(2 n+1)}{6} \quad$ sebagai berikut:

$$
\begin{aligned}
\sum_{i=1}^{n}(13 i)^{2} & =\frac{169 n(n+1)(2 n+1)}{6} \\
& =\frac{169.4 r(4 r+1)(2(4 r)+1)}{6} \\
& =\frac{169.4 r(4 r+1)(8 r+1)}{6} \\
& =\frac{169.2 r(4 r+1)(8 r+1)}{3} \\
& =\frac{2.169 r(4 r+1)(8 r+1)}{3} \\
& =2 R
\end{aligned}
$$

Jadi untuk $R$ suatu bilangan bulat diperoleh bahwa $\sum_{i=1}^{n}(13 i)^{2}$ habis dibagi 2 untuk $n=4 r$.

Kemudian dengan mensubstitusikan $n=4 r-1$ ke dalam persamaan $\sum_{i=1}^{n}(13 i)^{2}=\frac{169 n(n+1)(2 n+1)}{6}$ diperoleh:

$$
\begin{aligned}
\sum_{i=1}^{n}(13 i)^{2} & =\frac{169 n(n+1)(2 n+1)}{6} \\
& =\frac{169(4 r-1)((4 r-1)+1)(2(4 r-1)+1)}{6} \\
& =\frac{169(4 r-1)(4 r)(8 r-1)}{6} \\
& =\frac{169.2 r(4 r-1)(8 r-1)}{3} \\
& =\frac{2.169 r(4 r-1)(8 r-1)}{3} \\
& =2 R
\end{aligned}
$$

Jadi untuk $R$ suatu bilangan bulat diperoleh bahwa $\sum_{i=1}^{n}(13 i)^{2}$ habis dibagi 2 untuk 
$n=4 r-1$, sehingga terbukti Teorema 3 untuk $\sum_{i=1}^{n}(13 i)^{m}$ dengan $m=2$.

Pembuktian Teorema 3 untuk $m=3$ diperoleh dengan mensubstitusikan $n=4 r$ ke dalam persamaan $\sum_{i=1}^{n}(13 i)^{3}=\frac{2197 n^{2}(n+1)^{2}}{4}$ sebagai berikut:

$$
\begin{aligned}
\sum_{i=1}^{n}(13 i)^{a} & =\frac{2197 n^{2}(n+1)^{2}}{4} \\
& =\frac{2197(4 r)^{2}(4 r+1)^{2}}{4} \\
& =\frac{219716 r^{2}(4 r+1)^{2}}{4} \\
& =21974 r^{2}(4 r+1)^{2} \\
& =2.21972 r^{2}(4 r+1)^{2} \\
& =2 R
\end{aligned}
$$

Jadi untuk $R$ suatu bilangan bulat diperoleh bahwa $\sum_{i=1}^{n}(13 i)^{3}$ habis dibagi 2 untuk $n=4 r$.

Kemudian dengan mensubstitusikan $n=4 r-1 \quad$ ke dalam persamaan $\sum_{i=1}^{n}(13 i)^{3}=\frac{2197 n^{2}(n+1)^{2}}{4}$ diperoleh:

$$
\begin{aligned}
\sum_{i=1}^{n}(13 i)^{a} & =\frac{2197 n^{2}(n+1)^{2}}{4} \\
& =\frac{2197(4 r-1)^{2}((4 r-1)+1)^{2}}{4} \\
& =\frac{2197(4 r-1)^{2}(4 r)^{2}}{4} \\
& =\frac{2197.16(r)^{2}(4 r-1)^{2}}{4} \\
& =21974 r^{2}(4 r-1)^{2} \\
& =2.21972 r^{2}(4 r-1)^{2} \\
& =2 R
\end{aligned}
$$

Jadi untuk $R$ suatu bilangan bulat diperoleh bahwa $\sum_{i=1}^{n}(13 i)^{3}$ habis dibagi 2 untuk $n=4 r-1$, sehingga terbukti Teorema 3 untuk $\sum_{i=1}^{n}(13 i)^{m}$ dengan $m=3$.

Pembuktian Teorema 3 untuk $m=4$, 5, 6, 7, 8, 9, 10 dapat dibuktikan dengan mengunakan cara yang sama.

\section{KESIMPULAN DAN SARAN}

Hasil yang diperoleh adalah karakteristik sisa pembagian dari $\sum_{i=1}^{n}(13 i)^{m}$ oleh pembagi 2 sebagai berikut:

2| $\sum_{i=1}^{n}(13 i)^{m}$ untuk $n=4 r$ atau $n=4 r-1$

Bagi pembaca yang tertarik dengan tulisan ini, disarankan agar membahas tentang analisis sisa pembagian sigma bilangan prima berpangkat lainnya.

\section{DAFTAR PUSTAKA}

A. G. Aksoy \& M. A. Khamsi. (2010). A Problem Book in Real Analysis, Springer, New York.

Baker A. (1984). The Theory of Numbers, Cambridge University Press, Cambridge.

Burton D.M. (2010). Elementary Number Theory, Seventh Edition, University of New Hampshire, Durham.

Clark W. E. (2003). Elementary Number Theory, Department of Mathematics University of South Florida, Florida.

Gulliver T.A. (2010). Divisibility of Sums of Powers of Even Integers, International Journal of Pure and Applied Mathematics, 64; 191198.

Gulliver T.A. (2010). Divisibility of Sums of Powers of Odd Integers, International Mathematical Forum, 5; 3059-3066.

Gulliver T.A. (2012). Sums of Powers of Intengers Divisible by Three, International Journal Contemp. Math. Sciences, 7; 1895-1901.

Irawati, A., Sarindat, E., Pratikno, dan Ardana, W.B. (2008). Mahir Matematika untuk SMK (Non Teknik) kelas IX. Pusat Perbukuan 
Departemen Pendidikan Nasional Jakarta.

Koshy T. (2007). Elementary Number Theory with Aplications Second Edition, Academic Press, London.

Mashadi \& Abdul Hadi. (2017). Analisis I, UR Press, Pekanbaru.

M. H. Potter. (1998). Basic Element of Real Analysis, Springer-Verlag, New York.

Stark H. M. (1998). An Introduction to Number Theory, Markham Publishing Company, Chicago.

Suprijanto D. (2015). Observation on Sums of Powers of Intengers Divisible by Five, Applied Mathematical Sciences, 9; 3679 - 3686.

Suprijanto D. dan Rusliansyah (2014). Observation on Sums of Powers of Intengers Divisible by Four, Applied Mathematical Sciences, 8; 2219 - 2226. 